\title{
IMPLEMENTASI PROGRAM GERAKAN SEKOLAH MENYENANGKAN (GSM) DALAM MENGATASI BULLYING DI SMPN 2 SLEMAN
}

\section{IMPLEMENTATION OF FUN SCHOOL MOVEMENTS TO OVERCOMING BULLYING IN SMP N 2 SLEMAN}

\author{
Lustianti Anggita Yuni Pratiwi \\ Filsafat dan Sosiologi Pendidikan. Kebijakan Pendidikan FIP UNY, \\ lustianti.anggita2016@student.uny.ac.id
}

\begin{abstract}
Abstrak
Pelitian ini bertujuan untuk mendeskripsikan implementasi program Gerakan Sekolah Menyenangkan (GSM) dalam mengatasi bullying di SMP N 2 Sleman. Aspek yang diteliti meliputi imp $\square$ ementasi program GSM secara umum, kegiatan program GSM dan faktor pendukung dan penghambat imp $\square$ ementasi program tersebut dalam mengatasi bullying. Penelitian ini mengacu konsep imp $\square$ ementasi kebijakan Van Metter dan Van HornPenelitian ini menggunakan metode kualitatif deskripstif. Subjek penelitian ini meliputi kepala sekolah, guru bimbingan konseling, guru tim GSM dan siswa. Teknik pengumpulan data menggunakan observasi, wawancara dan dokumentasi. Teknik analisis data, reduksi data, penyajian data, dan penarikan kesimpulan. Hasil penelitian menunjukkan bahwa implementasi tersebut sesuai dengan teori van metter dan van horn yang terdiri dari standar dan sasaran, sumber daya, karakteristik organisasi, disposisi, hubungan antar organisasi dan kondisi lingkungan berjalan dengan baik dan semestinya. Kegiatan program GSM dalam mengatasi bullying adalah kegiatan sosialisasi, circle time, pagi berbagi, hearing, dan beberapa penerapan zona kelas. Faktor yang mendukung keberhasilan GSM di SMP N 2 Sleman adalah dukungan dari semua elemen sekolah dan faktor penghambat program GSM adalah masih ada beberapa guru dan siswa yang belum beradaptasi dengan adanya program tersebut.
\end{abstract}

Kata kunci : program, Gerakan sekolah Menyenangkan (GSM), bullying

\begin{abstract}
This research aims to describe the implementation of the Fun School Movement (GSM) program in dealing with bullying in SMP N 2 Sleman. Aspects studied in the implementation of fun school movement program activities and supporting and inhibiting factors for the implementation of this program. this research to the concept of Van Metter and Van Horn policy implementation.This research uses descriptive qualitative method. The subjects of this study include the principal, counseling guidance teacher, GSM team teacher and students. Data collection techniques using observation, interviews and documentation. Data analysis techniques, data reduction, data presentation, and drawing conclusions. The results showed that the implementation was in accordance with the van metter and van horn theory which consisted of standards and targets, resources, organizational characteristics, dispositions, relations between organizations and environmental conditions running well and properly. GSM program activities in dealing with bullying are socialization activities, circle time, morning sharing, hearing, and some class zone applications. The factors that support the success of GSM in SMP N 2 Sleman are the support of all elements of the school and the inhibiting factors of the GSM program are there are still some teachers and students who have not adapted to the existence of the program.
\end{abstract}

Keywords: programs, Fun school movements (GSM), bullying 


\section{PENDAHULUAN}

Sekolah sebagai faktor penentu bagi perkembangan kepribadian siswa tidak hanya pengetahuan atau cara berpikir namun untuk bersikapmaupun cara berpriilaku untuk mengantarkan manusia menuju ke masa yang akan datang. Dalam hal ini yang dibutuhkan adalah kekeluargaan, kesejajaran, kasih sayang, dan kebebasan bertanggung jawab. Namun, seiring berjalannya waktu terjadi perubahan peradaban dan perubahan paradigma pendidikan. Sekolah nyangnseharusnya mendewasakan tereduksi menjadi menggurui dan digurui atau hanya sekedar pengajaran saja. Lembaga pendidikan Indonesia saat ini khususnya pada tingkat sekolah, seharusnya menciptakan paradigma pendidikan yang menyenangkan agar siswa bahagia dan betah untuk di sekolah. Kekeluargaan, kasih sayang, kebebasan mengungkapkan diri siswa, sedikit demi sedikit mulai menghilang dari sebuah lembaga pendidikan yang dikenal dengan sekolah.

Kondisi dimana banyak sekolah yang tidak menyenangkan menurut web dan berita di media cetak dibuktikan dengan masih banyak isu-isu masalah pendidikan yakni pemerataan pendidikan, efektifitas dan efisiensi juga masalah minimnya fasilitas sekolah. Selain itu rutinitas harian sekolah sering membuat siswa frustasi seperti banyaknya kegiatan sekolah, jadwal pelajaran yang padat, pekerjaan rumah (PR) yang selalu menumpuk, kegiatan les/privat di sore hari yang membuat siswa semakin terampas hak-haknya sebagai anak. Siswa dianggap sebagai robot yang harus mengikuti program otaknya untuk menyerap semua materi pelajaran dan melakukan semua kegiatan sekolah dan kasus yang paling banyak terjadi yaitu kasus bullying di lingkungan sekolah. Akan tetapi beberapa waktu ini telah ada gagasan-gagasan atau inovasi baru untuk merekonstruksi kembali pendidikan di negeri ini yaitu melalui program Gerakan sekolah Menyenangkan atau di kenal dengan sebutan GSM.

GSM merupakan sebuah program inovatif pembelajaran bertujuan melakukan transformasi pola pendidikan formal menjadi lebih kolaboratif, inklusif, dan menarik guna mendorong kemampuan diri siswa. GSM merumuskan konsep sekolah masa depan yakni sekolah menyenangkan yang memberi ruang tumbuhnya keunikan potensi setiap anak. Selain itu GSM juga sebagai strategi dalam mengatasi permasalahan yang dialami oleh kebanyakan sekolah baik tingkat sekolah dasar, menengah maupun atas yaitu pada kasus bullying.

Implementasi UU Perlindungan Anak menemukan relevansinya ketika di Indonesia pada saat ini terjadi banyak kekerasan. Fenomena tentang bullying, kekerasan dan kejahatan seksual, perdagangan anak dan kejahatan terhadap anak yang mana sudah dalam kondisi yang memprihatinkan, bahkan menjadi ancaman terhadap anak. Hal tersebut sebagai pondasi juga diciptakannya program GSM sekaligus untuk mengatasi kasus bullying yang mana diharapkan program tersebut dapat mengubah karakter siswa sehingga kasus bullying dapat teratasi.

Kasus bullying terjadi di Indonesia khususnya di lembaga pendidikan formal seperti SD,SMP, SMA maupun SMK. Komisi Perlindungan Anak Indonesia (KPAI) mencatat dalam kurun waktu 9 tahun, dari 2011 sampai 2019, ada 37.381 pengaduan kekerasan terhadap anak. Untuk bullying baik di pendidikan maupun sosial media, angkanya mencapai 2.473 laporan dan trennya terus meningkat. Banyaknya kasus kekerasan di sekolah menunjukkan bahwa sekolah belum mampu menciptakan suasana aman dan nyaman bagi siswa Hal tersebut sangat menjadi perhatian khusus dalam pendidikan di Indonesia khususnya pada lembaga pendidikan formal, sehingga pada instansi lembaga pendidikan formal berusaha mengatasi fenomena tersebut salah satunya melalui program GSM, dengan demikian jika sekolah dapat membuat siswa senang dan bahagia akan berdampak pula pada pembentukan prilaku siswa yang mana tidak saling membenci dan tidak ingin melakukan tindakan bullying.

SMP N 2 Sleman sebagai salah satu sekolah 
yang menerapkan GSM sejak tahun 2018 dan mengalami perubahan yang signifikan terutama pada kasus bullying. Sebagaimana yang dikatakan oleh Kepala Sekolah SMP N 2 Sleman pada workshop GSM SMP N 2 Sleman yaitu sekolah mengalami banyak perubahan setelah diterapkannya program GSM salah satunya yaitu penurunan terkait pemberian sanksi, berkurangnya praktik senioritas antara kakak kelas dan adik kelas serta laporan masalah di kelas berkurang bahkan tidak ada. Hal ini juga dapat dibuktikan dengan data konseling di dalam bimbingan konseling yang tahun pertahun semakin menurun dan untuk tahun ini justru tidak ada kasus terkait bullying. Dengan demikian Penulis tertarik untuk melakukan Penelitian tersebut.

Penelitian ini bertujuan untuk mendeskripsikan bagaimana Implementasi GSM di SMPN 2 Sleman, yang mana menjadikan sekolah tersebut dapat mengatasi bullying di sekolah, karena saat ini masalah umum dan banyak terjadi di sekolah dan belum sepenuhnya teratasi adalah masalah pada kasus bullying. Sehingga peneliti ingin melakukan penelitian yang berjudul "Implementasi Gerakan Sekolah Menyenangkan (GSM) dalam mengatasi bullying di SMP N 2 sleman.

\section{Jenis Penelitian \\ METODE PENELITIAN}

Penelitian ini merupakan penelitian deskripstif dengan menggunakan pendekatan kualitatif. Pendekatan kualitatif adalah metode penelitian yang berlandaskan pada filsafat postpositivisme, digunakan untuk meneliti pada kondisi obyek yang alamiah, (sebagai lawannya adalah eksperimen) dimana peneliti adalah sebagai instrument kunci, teknik pengumpulan data dilakukan secara triangulasi (gabungan), analisis data bersifat induktif/kualitatif, dan hasil penelitian kualitatif lebih menekankan makna daripada generalisasi (Sugiyono, 2015: 9).

Penelitian yang dilakukan relevan dengan beberapa skripsi atau jurnal yang lain yaitu pada jurnal Dyoty Auliya Vilda Ghasya (2018) yang berjudul "Gerakan Sekolah Menyenangkan dan Ramah Anak (GSMRA) Sebagai Wujud Rekonstruksi Pelaksanaan Pendidikan Pada Jenjang Sekolah Dasar". Hasil dari junal tersebut yaitu mendeskripsikan terkait apa yang dimaksud Gerakan Sekolah Menyenangkan dan Ramah Anak sebagai wujud Rekonstruksi Pelaksanaan Pendidikan pada Jenjang Sekolah Dasar. Persamaan dengan Penelitian penulis yaitu: sama-sama mendeskripsikan terkait Gerakan Sekolah Menyenangkan. Sedangkan perbedaanya penulis tidak meneliti tentang Ramah anak dan Penelitian penulis di SMP N 2 Sleman.

Skripsi dari Asri Ramadhani (2017) yang berjudul "Persepsi Kepala Sekolah, Guru, dan Siswa Terhadap Sekolah yang Menyenangkan di SD Muhammadiyah Program Khusus Kota Barat Surakarta". Hasil dari skripsi tersebut yaitu persepsi kepala sekolah, guru dan siswa terhadap sekolah yang menyenangkan tersebut sangat baik sesuai dengan masing-masing tugas yang sudah diterapkan, berperan penuh, dan optimal. Persamaan dengan Penelitian penulis yaitu sama-sama meneliti terkait sekolah yang menyenangkan. Sedangkan perbedaannya aitu dalam segi judul, tempat dan peneliti terfokus pada strategi dalam mengatasi bullying bukan terkait presepsi.

Skripsi dari Sisca Indriyani (2019) yang berjudul "Analisis Perilau Bullying Siswa Sekolah Menengah Atas Al-Azhar 3 Bandar Lampung Tahun 2018/2019”. Hasil dari skripsi tersebut yaitu SMA Al-Azhar 3 Bandar Lampung masih sangat tinggi angka prilaku bullyingnya mencapai 99,54\%. Bentuk perilaku bullying yang paling tinggi dilakukan siswa yaitu bullying verbal yang mencapai 210 siswa dari keseluruhan sampel yang diteliti. Persamaan dengan Penelitian penulis yaitu meneiti sama terkait bullying. Sedangkan perbedaanya dari segi judul, tempat dan fokus Penelitian berbeda.

\section{Tempat dan waktu penelitian}

Penelitian ini dilaksanakan di SMP N 2 Sleman Kecamatan Sleman, Kabupaten 
Daerah Istimewa Yogyakarta. Observasi ini dilaksanakan pada bulan Februari-Maret 2020.

\section{Subjek Penelitian}

Pada penelitian ini subjek yang digunakan adalah subjek penelitian ini yang meliputi kepala sekolah, guru bimbingan konseling, guru TIM GSM dan siswa.

\section{Data, Instrumen, dan Teknik Pengumpulan Data}

Penelitian ini bertujuan untuk mendeskripsikan implementasi program Gerakan Sekolah Menyenangkan (GSM) dalam mengatasi bullying di SMP N 2 Sleman. Data tersebut diperoleh melalui wawancraa, observasi dan studi dokumentasi.

Instrumen penelitian merupakan alat bantu yang dipilih dan digunakan oleh peneliti dalam kegiatan mengumpulkan data agar kegiatan tersebut menjadi sistematis dan mudah (Arikunto, 2005 : 101). Instrumen yang digunakan dalam penelitian ini adalah pedoman wawancara, pedoman observasi dan pedoman dokumentasi yang disusun berdasarkan pada kisi-kisi instrumen penelitian.

\section{Teknik Analisis Data}

Menurut Sugiyono (2015: 244) menyatakan bahwa analisis data adalah proses mencari dan mneyusun secara sistematis data yang diperoleh dari hasil wawancara, catatan lapangan, dan dokumentasi, dengan cara mengorganisasikan data ke dalam kategori, menjabarkan ke dalam unit-unit, melakukan sintesa, menyusun ke dalam pola, memilih mana yang penting dan yang akan dipelajari, dan membuat kesimpulan sehingga mudah dipahami oleh diri sendiri maupun orang lain. Teknik analisis data dalam penelitian ini menggunakan teknik analisis data interactive model dari Miles dan Huberman dengan langkah-langkah pengumpulan data, reduksi data, penyajian data dan penarikan kesimpulan.

\section{HASIL PENELITIAN DAN PEMBAHASAN}

SMP N 2 Sleman menerapkan program GSM sejak tahun ajaran 2018/2019 dengaan tujuan menciptakan lingkungan sekolah menyenangkan dan nyaman. Latar belakang SMP N 2 Sleman menerapkan program GSM yaitu 1) Mendapatkan informasi terkait program gsm dari kepala UPT Yandik kecamatan Ngaglik kabupaten Sleman,2) Menghadiri acara GSM di University club UGM bersama pendiri GSM yaitu Muhammad rizal, 3) Menghadiri workshop di Dinas Pendidikan Kabupaten Sleman, 4) Kepala Sekolah SMP N 2 Sleman tertarik dan memutuskan untuk menerapkan program GSM di SMP N 2 Sleman dengan tujuan mencipatakan pendidikan yang menyenangkan dan memanusiakan.

Dalam proses implementasi kebijakan atau program menurut Van Meter dan Van Horn terdapat beberapa variabel penentu kinerja implementasi kebijakan atau program yaitu: standar dan tujuan kebijakan, sumberdaya, karakteristik organisasi, hubungan antar organisasi, disposisi, dan kondisi lingkungan. Adapun pembahasan implementasi program GSM di SMP N 2 Sleman berdasarkan hasil penelitian menggunakan konsep implementasi kebijakan atau program dari Van Metter dan Van Horn adalah sebagai berikut: a) Standar dan Tujuan Program yaitu Suatu program memerlukan standar dan tujuan yang jelas sehingga dalam implementasinya dapat sesuai dengan harapan dan sesuai dengan tujuan yang telah ditetapkan. Standar kebijakan atau program GSM di SMPN 2 Sleman dapat dilihat dari 4 pilar utama GSM sebagai berikut: a) learning environment (pembentukan lingkungan belajar yang positif) melalui penerapan zona-zona yang mempunyai nilai dan makna positif di setiap kelas, masing- masing lingkungan kelas terdapat taman, dan terdapat banner yang bertulis "pastikan radius 2 meter dari anda bersih", hal ini bermaksud agar siswa dipastikan menyadari kebersihan 
lingkungan dengan melihat sampah atau membuang sampah yang berserakan di tempat sampah sehingga dipastikan lingkungan sekolah bersih. b) Pedagogical practice and assessment (proses pembelajaran dan penilaian), dibuktikan dengan dibuktikan ketika pembelajaran guru mendengarkan apa keinginan siswa dan sebelum memulai pembelajaran guru memastikan kondisi siswa agar siswa tetap fokus dalam mengikuti kegiatan belajar mengajar dan guru memberikan penghargaan dikelas bukan hanya pada siswa yang berprestasi namun pada siswa yang memiliki karakter yang positif. c) school connectedness (keterhubungan antara sekolah dengan orang tua dan stake holder), dibuktikan dengan dibuktikan dengan adanya keterlibatan orang tua dalam program GSM yang dinamakan paguyupan orang. Orang tua ikut berpartisipasi dalam semua hal terkait program GSM baik penataan maupun pendanaan sesuai dengan kebutuhan siswa dan kondisi kelas.dan d) Character development (pengembangan karakter) dibuktiikan dengan kegiatan sekolah dalam penyelenggaraan program GSM maupun tatanan kelas seperti penerapan zona-zona, semua kegiatan dan bentuk tatanan kelas memiliki nilai dan makna positif sehingga dapat membentuk karakter siswa yang positif.. Hal ini sesuai dengan hasil penelitian berupa wawancara maupun pengamatan peneliti bahwa 4 pilar tersebut sebagai standar dalam penerapan program GSM dan masing-masing pilar telah dilaksanakan di SMP N 2 Sleman baik di dalam kelas maupun dilingkungan sekolah. Sedangkan berdasarkan hasil penelitian, adapun tujuan program GSM di SMP N 2 Sleman meliputi: 1) menciptakan pendidikan yang menyenangkan dan memanusiakan, 2) menjadikan rumah kedua bagi siswa, dan 3) menciptakan proses pembelajaran yang lebih aktif. Dengan demikian pendidikan sekolah menyenangkan akan berdampak kepada perubahan karakter siswa, karena paradigma pendidikan menyenangkan menciptakan tumbuhnya karakter dalam diri siswa menjadi baik dan kasus bullying pun dirasa akan teratasi dengan sendirinya.

Keberhasilan proses implementasi GSM sangat tergantung dari kemampuan memanfaatkan sumber daya yang tersedia. Menurut Brian dan Lewis dalam Hasbullah (2016: 96) untuk dapat menerapkan kebijakan atau program yang sempurna maka, dibutuhkan perpaduan sumbersumber yang diperlukan harus benar-benar ada atau tersedia. Sumber daya manusia yang terlibat dalamimplementasi program GSM di SMP N 2 Sleman adalah semua warga sekolah meliputi kepala sekolah, guru, tenaga kependidikan, siswa SMP N 2 Sleman dan orang tua siswa SMPN 2 Sleman. Sumber daya dana untuk kegiatan program GSM SMP N 2 Sleman yaitu kegiatan sosialisasi dari sekolah melalui dana sekolah sedangkan untuk semua kegiatan atau bentuk tatanan kelas selain sosialisasi melalui pendanaan orang tua yang masing-masing kelas sudah dibentuk dan dinamakan paguyupan kelas. Sumber daya sarana dan prasarana yang dimiliki SMP N 2 sleman untuk mendukung dalam implementasi program GSM yaitu sesuai dengan kebutuhan kelas.

Karakteristik agen pelaksana terdiri dari struktur organisasi dan pembagian tugas dalam melaksanakaan program tersebut.

Dalam sruktur organisasi program GSM, SMP N 2 Sleman mempunyai struktur organisasi yaitu penanggung jawab, ketua tim GSM dan anggota. Sedangkan terkait pembagian tugas program GSM SMP N 2 Sleman belum memiliki pembagian tugas secari rinci, akan tetapi tim GSM melaksanakan tugasnya dengan saling bekerjasama sesuai dengan kemampuan dari masing- masing guru ketika mengikuti berbagai undangan sosialisasi atau tamu yang hadir di SMP N 2 Sleman terkait program GSM. Menurut Edward III dalam hasbbullah (2016: 99) disposisi berkenaan dengan kesediaan dari para implementator untuk mengeksekusi kebijakan pendidikan tersebut. Kecakapan 
saja tidak mencukupi, tanpa

kesediaan dan komitmen untuk melaksanakan kebijakan atau program. SMP N 2 Sleman menerapkan

programnGSM ini dengan bertujuan untuk menciptakan sekolah yang menyenangkan, sehingga kepala sekolah memutuskan untuk menerapkannya program tersebut karena tujuan tersebut sehingga komitmen kepala sekolah sangat bersungguh- sungguh untuk menciptakan pendidikan yang menyenangkan dan memanusiakan. Sedangkan kecakapan implementator dalam melaksanakan program GSM berjalan dengan baik meskipun belum dibentuknya pembagian tugas secara rinci namun semua yang terkait dalam program GSM baik dari kepala sekolah, tim GSM, siswa maupun orang tua menjalin kerjasama yang berjalan dengan baik.

Komunikasi yang dibentuk antara agen pelaksana atau yang terlibat dalam pelaksanaan program GSM yaitu berjalan dengan semestinya karena antara agen pelaksana saling bekerjasama, dan antara yang terlibat yaitu orang tua murid juga saling bekerjasama maka dari itu dibentuknya paguyupan kelas di masingmasing kelas agar komunikasi berjalan dengan baik. Sedangkan Koordinasi yang dilakukan SMP N 2 Sleman antara lain koordinasi kepala sekolah baik dengan guru maupun orang tua siswa dan koordinasi masing- masing orang tua siswa dalam paguyupan orang tua untuk memenuhi kebutuhan siswa di masingmasing kelas berjalan dengan baik dan sesuai dibuktikan dengan kegiatan di sekolah maupun di masing-masing kelas dapat berjalan dengan semestinya dan mengalami perubahan yang positif sesuai dengan tujuan program gsm yang diterapkan.

kondisi lingkungan dari internal SMP N 2 Sleman mendapat dukungan dari semua pihak pelaksana program GSM yaitu dari dalam diri guru dan siswa yang mempunyai kemauan lebih dalam melaksanakan program tersebut dan berusaha serta mampu dalam menjalankan program tersebut. Sedangkan dukungan dari luar SMP N 2 Sleman yaitu dukungan dari orang tua siswa yang mau terlibat, bekerja sama dan mendanai apa yang dibutuhkan siswa sesuai dengan kondisi kelas masing-masing.

Kondisi bullying di SMP N 2 Sleman saat ini mengalami penurunan yang sangat drastis sejak diterapkannya program GSM Selain itu masalah-masalah siswa terkait bimbingan konseling hampir nihil. Hal ini juga dibuktikan dengan data konseling terkait bullying semakin menurun dan pada tahun ini tidak ada kasus yang tercatat terkait kasus bulying. Bentuk program GSM yang mendukung dalam mengatasi bullying baik kegiatan sekolah maupun penerapan zona-zona di masing- masing kelas meliputi sosialisasi kenakalan remaja, hearing yaitu kegiatan mendengarkan keluh kesah siswa, dan berusaha diatasi oleh guru,circle time yaitu kegiatan sharing yang dilakukan siswa, untuk ditemukan solusinya bersama-sama oleh siswa lain maupun guru, penggalangan dana untuk membaantu siswa lain yang mengalami kesulitas terkait fasilitas sekolah dan pemberian penghargaan berupa bintang keebaikan yang diberikan kepada siswa yang mempunyai karakter yang positif sehari- hari di kelas. Adapun penerapan zona kelas meliputi zona emosi yitu berisikan gambar emoticon siswa sesuai dengan perasaaan siswa saat itu juga ketika akan dilaksanakan kegiatan belajar mengajar. Jika salah satu dari siswa menggambar emoticon sedih, siswa diperintahkan untuk bercerita apa yang dirasakannya dan ditemukan solusi dari permasalahnnya oleh guru maupun siswa lain, zona kebaikan yaitu berisikan surat berupa kebaikan seperti tolong menolong antar sesama yang ditulis dalam bentuk ucapan terima kasih dan ditujukan kepada yang bersangkutan secara langsung dengan menuliskan nama, profil kelas yaitu berisikan profil masing-masing siswa seperti tempat tanggal lahir. Dan biasanya ketika ada salah satu siswa berulang tahun 
akan saling mendapatkan ucapan dan doa oleh teman-temannya. Dengan demikian dari masing-masing kegiatan atau pemberian zona- zona terkait dalam mengatasi bullying membuat siswa lebih mempunyai karakter yang positif seperti saling tolong menolong, peduli, saling menghargai, saling berbagi dan membuat siswa senang karena dari guru sendiri bisa menghargai dan mendengarkan pendapat siswa. hal ini mencipatakan karakter dalam diri anak untuk saling menyayangi kepada sesama teman sehingga cenderung anak tidak akan melakukan tindakan kekerasan atau bullying di sekolah.

Faktor pendukung dalam implementasi program GSM dalam mengatasi bullying di SMP N 2 Sleman yaitu partisipasi penuh dari warga sekolah yang meliputi kepala sekolah, guru dan siswa dimana semua warga sekolah mendukung penuh atas program GSM sehingga program tersebut berhasil diterapkan dan membawa perubahan yang sangat sigifikan dan juga partisipasi orang tua, dimana orang tua sangat berpartisipasi dalam program GSM tersebut terkait penataan ruang maupun pendanaan di kelas sesuai dengan kebutuhan siswa.

Faktor penghambat program GSM yaitu guru dan siswa, dimana terdapat sebagian kecil guru dan siswa yang merasa zona nyamannya terganggu seperti guru dan siswa yang terlalu egois, cuek dan tidak peduli itu akan merasa program GSM ini tidak nyaman baginya. Selain itu faktor penghambat lainnya yaitu terdapat pada sebagian kecil guru yang belum mendapatkan workshop terkait GSM dan dari pihak sekolah belum mengadakan pembelajaran based learning dalam setahun penerapan program GSM.

\section{SIMPULAN DAN SARAN Simpulan}

Implementasi program GSM sesuai dengan teori van metter dan van Horn yang meliputi standar sasaran yaitu standar program GSM melalui 4 pilar dan sasaran program untuk menciptakan sekolah yang menyenangkan dan memerdekakan, sumber daya terdiri dari semua warga SMP N 2 Sleman, sumber daya dana melalui pguyupan orang tua dan sarana prasarana sesuai dengan kebutuhan siswa. Dalam program gsm memiliki struktur organisasi yang terdiri dari kepala SMPN 2 Sleman sebagai penanggung jawab, ketua gsm, dan anggota dari tim gsm, masing-masing belum memiliki tugas yang spesifik, namun semua anggota dari tim GSM saling bekerjasama dalam pelaksanaan program GSM. Program ini bisa berjalan dengan baik karena dukungan, komitmen dan kecakapaan dari semua pihak yang terlibat baik dari guru tim gsm maupun orang tua siswa.

Kegiatan yang medukung dalam mengatasi bullying kegiatan sosialisasi kenakalan remaja, hearing (mendengarkan keluhan siswa), circle time (berbagi pemaslahan siswa untuk ditemukan solusinya secara bersama-sama), penggalangan dana (memberikn infak untuk dibelikan peralatan sekolah bagi siswa yang kurang mampu), pemberian penghargaan (pemberian intang kebaikan untuk siswa yang memiliki karakter positif), dan penerapan zona yaitu zona emosi, zona kebaikan, dan profil kelas. Masing-masing dari kegiatan tersebut meiliki nilai positif yitu saling tolong menolong, saling berbagi, menumbuhkan rasa empati, perhatian sehingga rasa untuk menyakiti, kekerasan social tidak akan terjadi karena masing-masing siswa kakternya sudah terbentuk dengan baik.

Faktor pendukung program GSM dalam mengatasi bullying yaitu partisipasi penuh dari warga sekolah baik kepala sekolah, guru, maupun siswa dan orang tua siswa turut berpartisipasi penuh juga daam pelaksanaan program gsm mulai dari penataan kelas sampai dalam pendanaan yang dibutuhkan siswa.

Faktor penghambat program gsm dalam mengatasi bullying yaitu faktor dari dalam diri guru dan siswa, dimana terdapat sebagian kecil guru dan siswa yang merasa 
zona nyamannya dan terdapat pada sebagian kecil guru yang belum mendapatkan workshop terkaait GSM dan dari pihak sekolah belum mengadakan pembelajaran based learning dalam setahun penerapan program gerakan sekolah menyenangkan.

\section{Saran}

Setelah melakukan penelitian tentang implementasi GSM dalam mengatasi bullying di SMP N 2 Sleman, maka peneliti memberikan saran sebagai berikut: 1) Dalam struktur organisasi tim GSM SMP N 2 Sleman bisa menetapkan masing-masing tugas dari tim GSM sesuai dengan 4 pilar yang sudah ditetapkan secara rinci agar lebih jelas dan berjalan lebih maksimal. 2) SMP N 2 Sleman perlu menetapkan Surat keputusan Kepala sekolah atau Peraturan yang secara khusus membahas terkait program GSM. 3) Sekolah perlu lebih memfasilitasi kebutuhan siswa dikelas terkait program GSM. 4) Dinas pendidikan perlu menetapkan Peraturan daerah terkait program GSM atau ditetapkannya program tersebut sebagai kebijakan, karena program tersebut adalah program yang berhasil dalam mengatasi kasus bullying, dimana kasus tersebut merupakan kasus yang semakin banyak terjadi di sekolah dan. 5) Melakukan lobbing pemerintah agar dapat diakui secara resmi

\section{DAFTAR PUSTAKA}

Arif Rohman. (2012). Kebijakan Pendidikan Analisis Dinamika Formulasi dan Implementasi. Yogyakarta : Aswaja Pressindo

Gerakan sekolah Menyenangkan. Di unduh darihttps://www.sekolahmenyenangk an.org

Ghasya Dyoty Aulia Vilda. (2018). Gerakan Sekolah Menyenangkan Dan Ramah Anak Sebagai Wujud Rekonstruksi Pelaksanaan Pendidikan Pada Jenjang Sekolah Dasar. Di unduh dari https://repository.stkipgetsempena.ac
Saldana., Miles \& Huberman. (2014). Qualitative Data Analysis. America : SAGE Publication

Sekolah Tidak Lagi Menyenangkan. Di unduh dari https://news.detik.com/opini/d$\underline{1125787 / \text { sekolah-tidak-lagi- }}$ menyenangkan

Sugiyono. (2007). Metode Penelitian Kuantitatif Kualitatif. Bandung: Alfabeta(2015). Metodem Penelitian Pendidikan. Bandung : Alfabeta.

Sukmadinata. Nana Syaodih (2013). Metode Penelitian Pendidikan.Bandung: PT Remaja Rosdakarya

Undang-Undang Republik Indonesia Nomor 20 Tahun 2003 Tentang Sistem Pendidikan Nasional. (2003) ----------. Nomor 35 Tahun 2014 Tentang Perlindungan Anak. (2014) 